\title{
Following food to its source
}

\author{
Review by Carrie A. Scrufari* \\ Vermont Law School
}

Review of Knowing $\mathrm{W}$ here it $\mathrm{C}$ omes $\mathrm{F}$ rom: $\mathrm{L}$ abeling Traditional Foods to Compete in a G lobal Mark et, by Fabio Parasecoli. (2018). University of Iowa Press, Iowa City. A vailable as paperback; 254 pages. Publisher's website: https:/ / www.uipress.uiowa.edu/ books/2017-fall/ knowingwhere-it-comes.htm

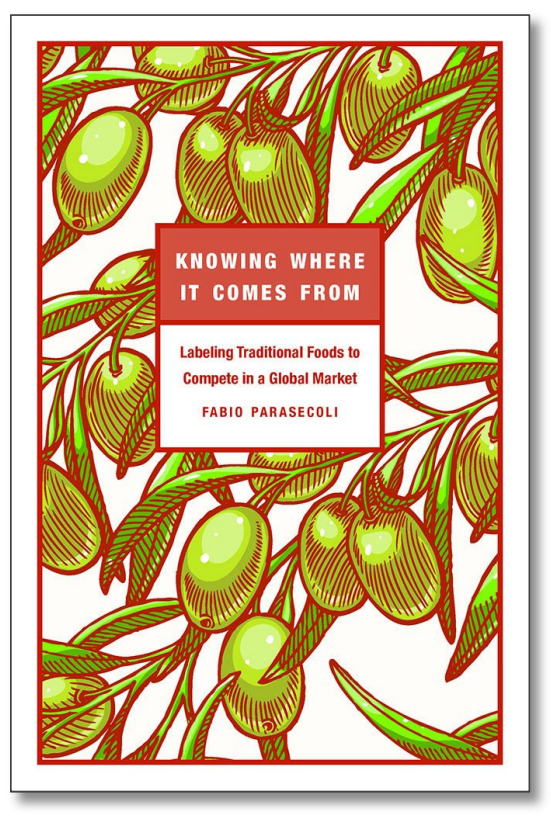

Submitted August 16, 2018 / Published online November 18, 2018

Citation: Scrufari, C. A. (2018). Following food to its source [Book review]. Journal of A griculture, F ood Systems, and Community D evelopment, 8(3), 231-232. https:/ / doi.org/ 10.5304/ jafscd.2018.083.017

Copyright @ 2018 by the Author. Published by the Lyson Center for Civic Agriculture and Food Systems. Open access under CC BY license.

W nowing W here it Comes From seeks to provide a

Wistory for the various labeling systems for foods now present in the global supply chain. Accordingly, author Fabio Parasecoli explains what a geographic indication is while comparing how these labels are used in various administrative systems, namely the sui generis system and the markbased system. Parasecoli refers to these indications and labeling schemes as "place-based labels" (p. 7). His stated goal is to "explore and assess the

* Carrie A. Scrufari, Esq. is an adjunct professor at Vermont Law School. She previously practiced in the Division of Consumer Protection at the New Y ork D epartment of State. She earned her LL.M degree in food and agricultural law and policy from Vermont Law School in D ecember 2016, where she also served as the senior fellow to the Center for Agriculture and Food Systems. She previously earned her J.D. from the University of Maryland in 2011, belongs to the Order of political, legal, and administrative apparatus that has been activated to identify and safeguard the connection between foods and their places of origin and to illustrate its different effects on all the stakeholders" (pp. 6-7).

While Parasecoli may ultimately achieve this goal, such success is contingent upon the reader's dedicated toil. Parasecoli does not follow the sage writing advice to never use two words where just one will do, leaving the reader to navigate a Faulkner style of writing with long, complicated

the Coif and Order of the Barrister, is a member of the New York State Bar, and has clerked at the New York State Appellate Division Fourth D epartment and the New York Court of Appeals. She has presented her work involving farm succession and food policy regulation at Harvard, Y ale, Pace, and Vermont Law Schools. She can be reached at cscrufari@ vermontlaw.edu. 
sentences often containing excessive verbiage. For example, at one point Parasecoli writes, "The increasing commercial and cultural relevance of local products and practices- especially those expressing long-lasting traditions- has led to attempts to describe, systematize, and regulate them through different kinds of classifications, juridical frameworks, and international conventions" (p. 6). Although Parasecoli takes pains to explain our globalized labeling scheme, his writing style often adds further complexity to an already complicated subject matter.

Nevertheless, Parasecoli is comprehensive in his treatment of the subject. His lists of abbreviations and acronyms at the beginning of his book are helpful, as is his chronology of laws, treatises, and administrative measures that are discussed in depth later. The first four chapters focus on intellectual property rights and their attendant rules and regulations. Within these chapters, he discusses everything from the industrialization and globalization of European food and wine products beginning in the $19^{\text {th }}$ century, to trade disputes before the World Trade O rganization to enforce the Agreement on Trade-Related Aspects of Intellectual Property Rights (TRIP) (i.e., whether "Parmesan" could be used to label cheese produced in $\mathrm{G}$ ermany), to tensions between traditionally produced foods and safety standards, to modern-day concerns over genetic engineering, crop contamination, and biopiracy. Parasecoli then shifts out of this discussion of legal frameworks and dedicates the remainder of his book to the history and effectiveness of the civil society association Slow Food and the role of various international bodies in protecting the integrity of locally produced foods.

A key strength of the book is Parasecoli's explanation of how legal frameworks have developed to support the labeling of locally or specially produced foods and how such a framework has provided alternative revenue schemes for rural communities struggling in depressed economic climates. His discussion comparing and contrasting the European-based geographic indicator (based on local traditions) with the United States' federal mark system is particularly informative. He correctly observes that in the U.S., such a system is premised upon "the right of the public to be correctly informed about the origin of the food it buys, not because of any particular characteristics attributed to the geography and environment of the area of origin, but rather because such misrepresentations were a form of fraud that could cause confusion among consumers" (p. 85).

D espite its strengths, Parasecoli's work reads largely like a dense treatise or textbook and would have benefited from incorporating some design principles to enhance its readability. For example, employing more subject matter headings and subheadings within chapters or including charts comparing the state of affairs in various regions such as India, Pakistan, Canada, the U.S., and China would have been helpful in allowing the reader to digest different pieces of information. Another common textbook design that could have aided the reader's comprehension is the use of sidebars to define and compare various key terms such as collective trademarks, certification trademarks, and certification marks. It also would have been useful for each chapter to contain a list of cited laws or international treaties to allow for quick referencing within the text. In sum, the book can be useful for gaining valuable knowledge about the historical development of various labeling schemes ... if the reader works hard enough to get it. 